\title{
Effects of Environmental Enrichment on Spatial Memory and Neurochemistry in Middle-Aged Mice
}

\author{
Karyn M. Frick, ${ }^{1,3}$ Nancy A. Stearns, ${ }^{2,3}$ Jing-Yu Pan, ${ }^{2}$ and Joanne Berger-Sweeney ${ }^{2,4}$ \\ ${ }^{1}$ Department of Psychology, Yale University, New Haven, Connecticut 06520, USA; ${ }^{2}$ Department of Biological Sciences, Wellesley College, \\ Wellesley, Massachusetts 02481, USA
}

\begin{abstract}
The present study compared the effects of environmental enrichment on spatial memory, glutamic acid decarboxylase (GAD) activity, and synaptophysin levels in middle-aged male and female mice. Prior to testing, a subset of 18-month-old male and female $\mathrm{C} 57 \mathrm{BL} / 6$ mice was housed with two to three toys and a running wheel in the home cage for up to $29 \mathrm{~d}$. Adult mice $(7 \mathrm{mo})$ of both sexes and the remaining middle-aged mice were group (social) housed, but not exposed to enriching objects. After the enrichment period, all mice were tested in a 1-day version of the Morris water maze, in which both spatial and nonspatial memory were assessed. Immediately after testing, the hippocampus and frontoparietal cortex were dissected, and GAD activity and synaptophysin levels were measured. Environmental enrichment reduced the age-related impairment in spatial acquisition and retention; relative to adult social controls, middle-aged enriched mice were unimpaired, whereas middle-aged social controls were impaired. This reduction was similar in middle-aged males and females. Enrichment did not affect cued memory in either sex. Although hippocampal GAD activity was increased by enrichment in males, all other neurochemical measurements were unaffected by enrichment or aging in either sex. These data suggest that environmental enrichment initiated at middle age can reduce age-related impairments in spatial memory in males and females, although the underlying neurobiological mechanisms of this effect remain unknown.
\end{abstract}

Senescence in humans and other mammals is commonly accompanied by impairments in learning and memory. Spatial memory, such as that used to navigate around the environment, is particularly vulnerable to aging in humans and animals such as rats and mice (Evans et al. 1984; Gage et al. 1984; Sharps and Gollin 1987; Gallagher and Pelleymounter 1988; Gower and Lamberty 1993; Frick et al. 1995, 2000b; Gallagher 1997). This decline may result from deterioration of brain regions critical for spatial memory, such as the neocortex and hippocampus. Although numerous drug treatments have been developed to reduce or prevent memory decline in rodent models of aging, a handful of studies suggest that a simple behavioral treatment, environmental enrichment, may effectively improve neural function and alleviate age-related memory dysfunction. In humans, for example, cognitive abilities are maintained longer in those who remain intellectually stimulated throughout their lives (Schaie 1993; Shimamura et al. 1995).

Environmental enrichment typically involves housing rats or mice in groups and allowing them to play with novel toys, traverse obstacles, and/or exercise in running wheels.

\footnotetext{
${ }^{3}$ These two authors contributed equally to this work.

${ }^{4}$ Corresponding author.

E-MAIL Jbergers@wellesley.edu; FAX (781) 283-3642.

Article and publication are at http://www.learnmem.org/cgi/doi/ $10.1101 / \mathrm{lm} .50703$
}

Enriched rodents are compared with two types of controls, generally termed isolated (singly housed) or social (group housed), neither of which are exposed to enriching stimuli. Among rats raised from weaning in an enriched environment, numerous neocortical alterations have been observed including increased cortical thickness, dendritic spines and branching, synaptic contacts and transmission, and neuron size (e.g., Diamond et al. 1964; Diamond 1967; Globus et al. 1973; Greenough and Volkmar 1973; Greenough et al. 1973, 1978; Green and Greenough 1986; for review, see Rosenzweig and Bennett 1996). Furthermore, enriched rats exhibit enhanced learning and memory abilities relative to isolated littermates, suggesting a functional role for the cortical alterations (Brown 1968; Greenough et al. 1972; Tees 1999; Woodcock and Richardson 2000). More recent work in adult rodents indicates that enrichment initiated at nearly any point in the lifespan can improve spatial and nonspatial memory (Nilsson et al. 1999; Rampon et al. 2000; Duffy et al. 2001; Tang et al. 2001; Williams et al. 2001), and enhance several aspects of hippocampal functioning such as long-term potentiation (Duffy et al. 2001), neurogenesis (Kempermann et al. 1997; Nilsson et al. 1999), dendritic spine growth (Rampon et al. 2000), and neurotrophin mRNA expression (Torasdotter et al. 1996, 1998). Moreover, enrichment in aging rodents can provide similar benefits. In aged rats and mice, enrichment initiated at either

LEARNING \& MEMORY 10:187-198 @ 2003 by Cold Spring Harbor Laboratory Press ISSN1072-0502/03 \$5.00

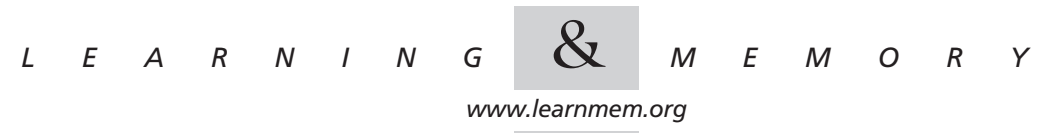


weaning or during old age results in such neural alterations as increased cortical thickness, dendritic branching, RNA content, and presynaptic vesicle number (Warren et al. 1982; Diamond et al. 1985; Greenough et al. 1986; Nakamura et al. 1999), reduced aging-induced hippocampal gliosis (Soffié et al. 1999), and increased cortical and hippocampal levels of the presynaptic protein synaptophysin (Saito et al. 1994; Frick and Fernandez 2003). Furthermore, enrichment in aged rats and mice reverses deficits in memory and other behaviors (Warren et al. 1982; Van Waas and Soffié 1996; Winocur 1998; Soffié et al. 1999; Frick and Fernandez 2003).

Much less is known about the effects of environmental enrichment in middle-aged rodents. This age group is critical, because it is during middle-age when spatial memory deficits begin to emerge (e.g., Frick et al. 1995, 2000b). Thus, initiating enrichment during middle age may prevent or postpone the onset of memory decline. In male rats, one year of enrichment initiated at 2 mo increases levels of nerve growth factor (NGF) and brain-derived neurotrophic factor, and improves spatial memory relative to isolated rats (Pham et al. 1999; Ickes et al. 2000). Among middle-aged female rats and mice, enrichment initiated during middle age increases occipital cortical dendritic branching relative to isolated controls (Green et al. 1983), and enhances both hippocampal neurogenesis and spatial memory in the Morris water maze relative to social controls (Kempermann et al. 1998).

However, several issues remain unclear. The first is whether the beneficial effects of enrichment are of a similar magnitude in middle-aged males and females. This may be an important issue, as enrichment-related sex differences have been reported in cortical and hippocampal dendritic branching (Juraska 1984; Juraska et al. 1985) and exploratory behavior (Joseph 1979), despite the fact that male and female rats interact with the enriched environment similarly (Juraska and Meyer 1986). A second issue concerns the control group with which enriched mice are compared. As illustrated above, enriched middle-aged rodents have been compared with both isolated and social control rodents. In aged rats, enrichment has much less of an effect on maze learning relative to social controls than it does relative to isolated controls (Winocur 1998). Thus, the fact that investigations in middle-aged males used isolated controls (Pham et al. 1999; Ickes et al. 2000), whereas studies in middleaged females have used both types of controls (Green et al. 1983; Kempermann et al. 1998), may confound the comparison of these studies. A final issue concerns the neurobiological mechanisms underlying the memory-enhancing effect of enrichment. No study has examined the effects of enrichment on the same neurobiological variables in middle-aged male and female mice. Given sex differences in dendritic branching in response to enrichment (Juraska 1984; Juraska et al. 1985), it may not be possible to gener- alize enrichment-induced neural alterations from one sex to the other

The present study was designed to examine the effects of environmental enrichment on spatial memory and neurochemistry in middle-aged males and females. Enriched mice were compared with social control mice because group housing is common in mouse colonies, and thus, this comparison addresses effects relative to normal housing conditions. To facilitate examination of relationships between enrichment-induced changes in memory and neurochemical measures, all behavioral testing was performed on the same day as tissue collection. To this end, we utilized a 1-day version of the Morris water maze, in which spatial and nonspatial memory could be tested within $3 \mathrm{~h}$ (Frick et al. 2000a). At the conclusion of behavioral testing, tissue from the frontoparietal cortex and hippocampus was collected for measurement of the following: activity of the enzyme glutamic acid decarboxylase (GAD), which synthesizes GABA, and the presynaptic vesicle protein synaptophysin. We have shown previously that GAD is altered in middleaged mice in a sexually dimorphic manner (Frick et al. 2002), such that increased GAD activity was associated with age-related spatial memory decline in middle-aged females, but not middle-aged males (Frick et al. 2000b, 2002). Thus, enrichment-induced memory improvements may be associated with reduced GAD activity in middle-aged females. Synaptophysin, a 38-kD calcium-binding glycoprotein found in the membranes of neurotransmitter-containing presynaptic vesicles, was measured as an index of synaptic plasticity. In rodents, age-related reductions in cortical or hippocampal synaptophysin have been reported (Saito et al. 1994; Chen et al. 1995), although reductions are sometimes not observed (Calhoun et al. 1998; Nicolle et al. 1999) or are restricted to specific hippocampal subregions (Smith et al. 2000). Despite these discrepancies, elevated synaptophysin levels are associated with better spatial memory in the water maze (Chen et al. 1995; Calhoun et al. 1998; Smith et al. 2000). Moreover, enrichment in aged male rats significantly increases presynaptic vesicles in the frontal cortex (Nakamura et al. 1999) and synaptophysin expression in the hippocampus and neocortex (Saito et al. 1994). Thus, modulation of synaptophysin may play a role in enrichment-induced mnemonic improvements in aging rodents. The present study is the first to examine this potential relationship in middle-aged rodents of either sex.

\section{MATERIALS AND METHODS}

\section{Subjects}

Subjects were adult (7-months-of-age) and middle-aged (18-monthsof-age) male and female $\mathrm{C} 57 \mathrm{BL} / 6$ mice obtained from the National Institutes on Aging colony at Charles River Laboratories. Mice were housed up to five per large mouse cage in a room with a 12:12 light/dark cycle (lights on at 06:00), and behavioral testing was performed during the light phase of the cycle. Food (Harlan Teklad

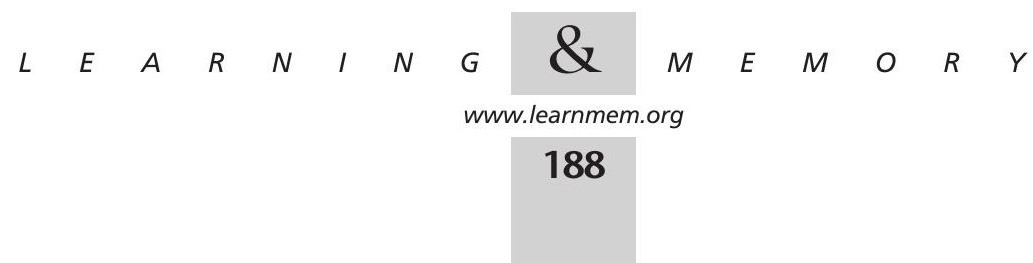


8640 Rodent Diet) and water were provided ad libitum. All mice were handled for $5 \mathrm{~d}$ prior to the start of enrichment to habituate them to being picked up by the experimenter. A subset of middleage males and females were then housed with running wheels and rodent toys (see below). Control mice of both ages were housed in groups, but not provided with wheels or toys in their home cages. This resulted in a total of six groups as follows: adult social control male $(n=18)$, adult social control female $(n=17)$, middle-aged social control male $(n=13)$, middle-aged social control female $(n=16)$, middle-aged enriched male $(n=9)$, and middle-aged enriched female $(n=11)$. All procedures conformed to the standards set forth in the National Institutes of Health Guide for the Care and Use of Laboratory Animals and were approved by the Institutional Animal Care and Use Committee of Wellesley College.

\section{Environmental Enrichment}

Enrichment was provided by means of objects placed inside the home cage (cage enrichment) to which the mice had 24-hour access. A running wheel $(13 \mathrm{~cm}$ in diameter) was always present, whereas other rodent toys were rotated daily. These items included plastic mouse toys in various shapes (e.g., boot, houses, dome, rectangle), PVC pipe fittings of different shapes and sizes, Critter Trial Puzzle Playgrounds in several configurations, a metal wire bridge, plastic slides attached to blocks, and small balls. Two or three of these toys were included in the cage each day along with a running wheel. Mice were tested in the 1-day water maze task in groups of eight or nine, and each mouse was killed after the completion of testing. Thus, the total duration of enrichment lasted for 25-29 d, depending on the day of behavioral testing. At least one mouse from each group was tested each day.

\section{Morris Water Maze}

A circular tank (103 cm in diameter) was filled with water (24 \pm $2^{\circ} \mathrm{C}$ ) and surrounded by various extramaze cues. The apparatus and procedure have been described in detail elsewhere (Frick et al. $2000 a, b)$. Briefly, the tank was divided into four quadrants, and four start positions were located at the intersections of the quadrants. Data were recorded using an automated tracking system (HVS Image). Prior to testing, all mice were habituated to the water and the platform using a four-trial shaping procedure in which a smaller ring $(55 \mathrm{~cm})$ was inserted inside of the tank. Each mouse was first placed on a visible lucite platform $(10 \times 10 \mathrm{~cm})$ for $10 \mathrm{sec}$, and then placed at three progressively further distances from the platform, where it was allowed $60 \mathrm{sec}$ to escape onto it. No data were collected during this procedure.

To test spatial and nonspatial reference memory within a single day, a 17-trial procedure was conducted as described previously (Frick et al. 2000a). This procedure involves 3 blocks of 4 spatial training trials with a hidden platform (12 total trials), 1 spatial probe trial in which the hidden platform is unavailable for escape for $30 \mathrm{sec}$, and 4 cued trials in which the hidden platform is replaced by a visible platform that moves to a new location for each trial. The trials were conducted as follows.

\section{Spatial Task Acquisition}

In these trials, the mice were trained to find a hidden platform using extramaze cues. A transparent lucite platform $(10 \times 10 \mathrm{~cm})$ was submerged beneath the surface of the water $(0.5 \mathrm{~cm})$ in the northwest quadrant of the tank. The sequence of four start positions $(\mathrm{N}, \mathrm{S}, \mathrm{E}, \mathrm{W})$ varied for each trial. Each mouse participated in 12 spatial trials, organized into 3 blocks of 4 trials ( 1 trial/start position within a block) separated by $30 \mathrm{~min}$. Each mouse was given $60 \mathrm{sec}$ to reach the platform, upon which it remained for $10 \mathrm{sec}$. If the platform was not located within $60 \mathrm{sec}$, the mouse was placed on it by the experimenter. The next trial started immediately after removal from the platform. After completion of the fourth trial of the block, the mouse was placed in its home cage for 30 min. Swim time $(\mathrm{sec})$, swim distance $(\mathrm{cm})$, and swim speed $(\mathrm{cm} / \mathrm{sec})$ were recorded. In addition, a corridor measure was calculated to examine whether the animals swam in a straight path from the start location to the platform. A corridor (14-cm wide) was drawn between the start location and the platform, and the ratio of the number of points measured in the corridor to total points sampled was multiplied by the ratio of pool area to the area of the corridor. Corridor ratios of $>1$ indicated preference for the corridor over other locations in the pool. For swim time and swim distance, lower numbers indicate better performance, whereas higher numbers indicate better performance for the corridor measure (i.e., a more direct route to the platform).

\section{Spatial Probe Trial}

To examine how well the mice had learned the location of the platform, one probe trial was conducted $30 \mathrm{~min}$ after completion of the spatial task. During this trial, the platform was collapsed and unavailable for escape for $30 \mathrm{sec}$. The platform was then raised and available for escape for an additional $30 \mathrm{sec}$. During the first $30 \mathrm{sec}$ of the probe trial, quadrant time (percentage of time spent in the quadrant containing the platform), proximity (average distance in centimeters to the platform; distances sampled 10 times/sec), and platform crossings (the number of times the location of the platform was crossed) were recorded. For quadrant time and platform crossings, higher numbers indicate better performance (more time spent in the correct quadrant and more crossings over the platform location), whereas lower numbers indicate better performance for proximity (i.e., shorter distances from the platform).

\section{Cued Task Acquisition}

To control for non-mnemonic aspects of water maze performance (e.g., motivation, swimming ability, visual acuity) and test nonspatial memory, a cued task was conducted 20 min after completion of the probe trial. A visible platform was raised just above the surface of the water. The platform was covered with tape and had a plastic circle ( $8 \mathrm{~cm}$ in diameter, $0.5-\mathrm{cm}$ thick) attached perpendicularly to it. The platform was moved to a different quadrant for each of the four trials. Swim time, swim distance, and swim speed were recorded.

\section{Neurochemical Assays}

Immediately following the last cued trial, each mouse was sedated briefly with $\mathrm{CO}_{2}$ and decapitated (Berger-Sweeney et al. 1994). The brain was removed immediately, and frontoparietal cortex and hippocampus were dissected bilaterally on ice. Tissue samples were weighed and stored at $-70^{\circ} \mathrm{C}$ until the day of assay. Samples were resuspended in $0.02 \%$ Triton X-100 in $0.1 \mathrm{mM}$ Tris (pH 7.4), sonicated with a probe sonicator, and centrifuged for $10 \mathrm{~min}$ at $10,000 \mathrm{~g}$. The supernatant was diluted with the same reagent to yield an 1:100 dilution of the original tissue; this dilution was designated the crude extract. This crude extract was further diluted as described below.

\section{GAD Activity}

Activity of the enzyme GAD, which synthesizes GABA, was determined from the amount of $\left[{ }^{14} \mathrm{C}\right] \mathrm{CO}_{2}$ formed by GAD action on

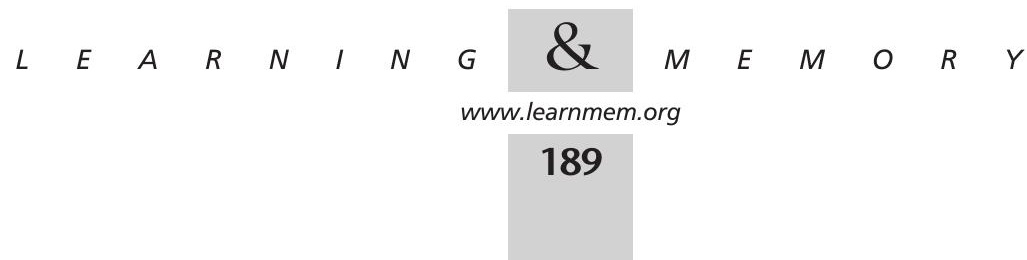


L-[1- $\left.{ }^{14} \mathrm{C}\right]$-glutamic acid (40-60 mCi/mmole, New England Nuclear) using a $\left[{ }^{14} \mathrm{C}_{\mathrm{CO}_{2}}\right.$ trapping technique to collect the radiolabeled product for scintillation counting (O'Connor et al. 1988). A detailed description of the assay procedures is provided elsewhere (Frick and Berger-Sweeney 2001; Frick et al. 2002). The protein content of the samples was measured using a Bradford protein assay (Bradford 1976). GAD activity was expressed as nanomole of product/ $\mathrm{hr} /$ milligram protein.

\section{Synaptophysin}

The relative amount of synaptophysin in the samples was determined in an antibody sandwich ELISA, which we developed in our laboratory, using previously published methods (Schlaf et al. 1996; Buttini et al. 2000). Because purified synaptophysin was not available for use as a standard, synaptophysin levels in the samples were calculated relative to the amount of synaptophysin in a known amount of whole mouse brain homogenate (termed mouse brain standard or MBS). Between each step of the assay, the plates were washed three times for $1 \mathrm{~min} /$ wash with room temperature PBS (pH 7.4). Ninety-six well Nunc-Immuno Plates with Maxisorp surface were coated with $2 \mu \mathrm{g} / \mathrm{mL}$ goat anti-mouse IgG Fc antibody (Chemicon International Inc.) in PBS, $0.02 \%$ sodium azide, and allowed to incubate overnight at $4{ }^{\circ} \mathrm{C}$. Plates were incubated at room temperature for $6 \mathrm{~h}$ and then were blocked for $30 \mathrm{~min}$ at room temperature with $350 \mu \mathrm{L}$ of block buffer (PBS at $\mathrm{pH} 7.4,0.5 \%$ BSA, $0.05 \%$ Tween $20,0.02 \%$ sodium azide). A total of $50 \mu \mathrm{L}$ of 0.75 $\mu \mathrm{g} / \mathrm{mL}$ monoclonal mouse anti-synaptophysin antibody (Clone SY 38, DAKO Corp.) in block buffer was then incubated in each well overnight at $4^{\circ} \mathrm{C}$. After the plates were incubated for an additional $2 \mathrm{~h}$ at room temperature, and then washed with PBS, $50 \mu \mathrm{L}$ of four different concentrations of whole mouse brain homogenate (tissue diluted to final concentrations of 1:8000, 1:16,000, 1:32,000, and 1:64,000) and of the brain test samples (tissue diluted to final concentrations of $1: 32,000)$ were placed in wells in triplicate. The plates were allowed to incubate overnight at $4{ }^{\circ} \mathrm{C}$, and then at room temperature for $1-1 / 2 \mathrm{~h}$. The wells were then blocked for $10 \mathrm{~min}$ with ELISA block buffer, and incubated at room temperature for $4-1 / 2 \mathrm{~h}$ with $50 \mu \mathrm{L}$ of a 1:5000 dilution of polyclonal rabbit antisynaptophysin antibody (DAKO Corp.) in ELISA block buffer. The plates were blocked for 10 min with ELISA block buffer without sodium azide, then incubated first for $30 \mathrm{~min}$ at room temperature, and then overnight at $4^{\circ} \mathrm{C}$ in $50 \mu \mathrm{L}$ of HRPO-conjugated goat antirabbit IgG antibody (Vector Laboratories) diluted 1:4000 in ELISA block buffer without sodium azide. The following morning, the plates were incubated for an additional $2 \mathrm{~h}$ at room temperature. After washing with PBS, $75 \mu \mathrm{L}$ of substrate solution $\left(0.03 \% \mathrm{H}_{2} \mathrm{O}_{2}\right.$, $0.1 \%$ 2,2'-Azino-bis [3-ethylbenzthiazoline-6-sulfonic acid] diammonium salt in $0.1 \mathrm{M}$ citric acid, $\mathrm{pH} 4.2$; Sigma Chemical Co.) was added to each well. This was allowed to incubate for 45-60 min before the plates were read at $405 \mathrm{~nm}$ using a Packard SpectraCount microplate photometer. To calculate the relative amount of synaptophysin in the samples, the absorbance of each of the four different concentrations of MBS was plotted versus the log of the total protein concentration to yield a standard curve. The equation of the straight line that resulted and the absorbance of each sample were used to determine the concentration of MBS that would have the absorbance exhibited by the sample. This concentration was divided by the total protein concentration of the sample (obtained from the protein assay) to yield the relative amount of synaptophysin in the sample versus the amount of synaptophysin in the mouse brain homogenate (termed MBS synaptophysin equivalent).

\section{Data Analysis}

Separate sets of analyses were performed for males and females, such that each set included three groups, adult social control, middle-aged social control, and middle-aged enriched. Spatial acquisition and cued task measures were averaged within a group for each block of four trials (spatial task) or single trial (cued task), and analyzed using a one-way repeated-measures analysis of variance (ANOVA) with Group as the independent variable (SuperANOVA, Abacus Concepts). One-way ANOVAs without repeated measures were performed on the probe trial and neurochemical measures. Fisher's protected least significant difference posthocs were performed to delineate between-group differences. To directly compare effects of enrichment on middle-aged males and females, a separate set of ANOVAs was performed as described above using middle-aged mice only (including all four middle-aged groups). To examine relationships among spatial memory, GAD activity, and synaptophysin levels, correlations were conducted between GAD and synaptophysin in each brain region and five measures of performance from the spatial task, swim time, swim distance, and corridor (values used were the sum of the three block averages), quadrant time, and proximity (Statview 5.0.1, SAS Institute, Inc.). Fisher's $r$ to $z$ tests measured statistical significance of the correlations.

\section{RESULTS}

\section{Subjects}

All mice were in good health and completed behavioral testing. Both the GAD and synaptophysin values of one middle-aged social control female were statistical outliers, and, therefore, were excluded from ANOVA and correlation analyses. One adult female, one adult male, and one middleaged enriched male were not assayed for synaptophysin. One adult female is missing a value for synaptophysin in the hippocampus.

\section{Acquisition and Retention of the Water Maze Task in Males}

A summary of the behavioral effects is presented in Table 1. Group means for spatial and cued platform trials measures collapsed across blocks are presented in Table 2. Enrichment reduced the age-related impairment in acquisition of the spatial task in middle-aged males. The main effect of Group (Table 2) was significant for the swim time $\left(F_{2,37}=3.4, P<0.05\right)$ and corridor $\left(F_{2,37}=4.4, P<0.02\right)$ measures, and nearly significant for the swim distance measure $\left(F_{2,37}=2.9, P=0.06\right)$. In both swim time and corridor, middle-aged social control males performed significantly worse than adult social control males $(P<0.02)$. In contrast, middle-aged enriched males were not significantly different from adult social control males, indicating a beneficial effect of enrichment. All three groups improved with testing, as suggested by significant Block effects in all three measures $\left(F_{2,74}=7.5-26.6, P<0.001\right.$; Fig. $\left.1 \mathrm{~A}-\mathrm{C}\right)$. The Block $x$ Group interaction was significant for swim time $\left(F_{4,74}=2.8, P<0.05\right.$; Fig. 1A $)$ and nearly significant for

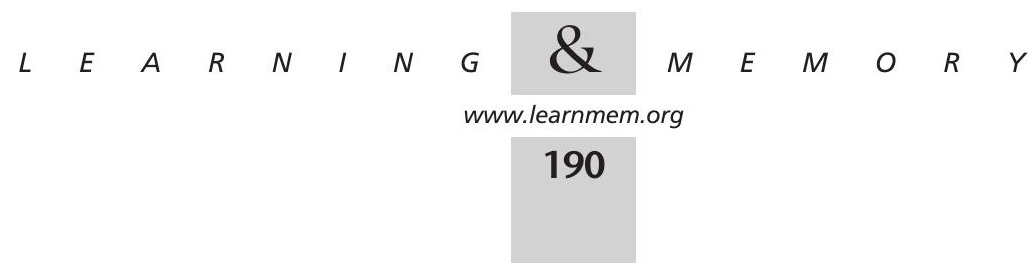


Table 1. Summary of the Behavioral Effects in Males and Females

\begin{tabular}{llll}
\hline Task & \multicolumn{1}{c}{ Measure } & Males & Females \\
\hline Spatial & Swim time & $X^{\mathrm{a}}$ & $X^{\mathrm{a}}$ \\
& Swim distance & - & $X^{\mathrm{a}, \mathrm{b}}$ \\
& Corridor & $\mathrm{X}^{\mathrm{a}}$ & $\mathrm{X}^{\mathrm{a}}$ \\
Spatial probe & Swim speed & - & - \\
& Quadrant time & - & - \\
& Proximity & $X^{\mathrm{a}}$ & $X^{\mathrm{a}}$ \\
Cued & Platform crossings & - & - \\
& Swim time & - & - \\
& Swim distance & - & - \\
& Swim speed & - & - \\
\hline
\end{tabular}

$X$ indicates a significant Group effect in the ANOVA.

aindicates a difference between adult and middle-aged social control groups of the same sex in the absence of a difference between adult social control and middle-aged enriched groups of the same sex.

bindicates a difference between middle-aged groups of the same sex.

-indicates a nonsignificant Group effect in Anova.

swim distance $\left(F_{4,74}=2.4, P=0.06\right.$; Fig. $\left.1 \mathrm{C}\right)$. Swim speeds did not differ among the groups (Table 2).

Enrichment also reduced age-related spatial memory decline in the spatial probe trial, as indicated by the proximity measure (Fig. 2B). In this measure, the Group effect was significant $\left(F_{2,37}=4.9, P<0.02\right)$ and posthoc tests indicated that middle-aged social control males, but not middle-aged enriched males, swam further from the platform location than adult social control males $(P<0.01)$. Neither quadrant time (Fig. 2A) nor platform crossings (Fig. 2C) differed significantly among the groups.

The cued task was not affected by age or enrichment. Neither the Group effect (Table 2) nor the Trial x Group interaction was significant for any measure. Significant Trial effects in swim time (Fig. 3A) and swim distance indicated improvement during the course of testing $\left(F_{3,111}=31.6\right.$ and 20.5 , respectively, $P<0.001)$.

\section{Acquisition and Retention of the Water Maze Task in Females}

Enrichment also reduced the age-related spatial acquisition impairment in females. The main effect of Group (Table 2) was significant for all three measures of cognitive performance, swim time, swim distance, and corridor $\left(F_{2,41}=3.4\right.$, 4.0 , and 3.8, respectively, $P<0.05)$. In all three measures, middle-aged social control females performed significantly worse than adult social control females $(P<0.02)$. In contrast, middle-aged enriched females were not significantly different from adult social control females in any measure. Further indicating a beneficial effect of enrichment, middle-aged enriched females exhibited significantly shorter swim distances than middle-aged social control females $(P<0.05)$. All groups improved similarly, as suggested by significant Block effects in all three measures $\left(F_{2,82}=8.1-\right.$ $16.4, P<0.001)$ in the absence of significant Block $x$ Group interactions (Fig. 4A-C). Swim speeds did not differ among the groups (Table 2).

The effect of enrichment on spatial memory in the probe trial was similar to that of males. As in males, the Group effect for the proximity measure (Fig. 5B) was significant $\left(F_{2,41}=4.5, P<0.02\right)$. Posthoc tests indicated that middle-aged social control females, but not middle-aged enriched females, swam further from the platform location than adult social control females $(P<0.01)$. The Group effect for quadrant time (Fig. 5A) was nearly significant $\left(F_{2,41}=3.1, P=0.057\right)$, suggesting a potential benefit on

Table 2. Groups Means for Platform Trial Measures in the Water Maze

\begin{tabular}{|c|c|c|c|c|c|}
\hline Sex & Task & Measure & $\begin{array}{c}\text { Adult } \\
\text { social control }\end{array}$ & $\begin{array}{l}\text { Middle-aged } \\
\text { social control }\end{array}$ & $\begin{array}{c}\text { Middle-aged } \\
\text { enriched }\end{array}$ \\
\hline \multirow[t]{7}{*}{ Male } & \multirow[t]{4}{*}{ Spatial } & Swim time & $30.6 \pm 2.2$ & $40.8 \pm 2.1^{\mathrm{a}}$ & $39.3 \pm 3.3$ \\
\hline & & Swim distance & $482.4 \pm 35.6$ & $612.8 \pm 31.7$ & $561.9 \pm 43.8$ \\
\hline & & Corridor & $2.7 \pm 0.3$ & $1.8 \pm 0.2^{\mathrm{a}}$ & $2.0 \pm 0.3$ \\
\hline & & Swim speed & $15.7 \pm 0.4$ & $14.7 \pm 0.4$ & $14.7 \pm 0.4$ \\
\hline & \multirow[t]{3}{*}{ Cued } & Swim time & $21.5 \pm 1.8$ & $27.2 \pm 2.4$ & $19.5 \pm 2.5$ \\
\hline & & Swim distance & $263.3 \pm 27.0$ & $323.5 \pm 40.0$ & $211.2 \pm 26.0$ \\
\hline & & Swim speed & $11.9 \pm 0.4$ & $11.3 \pm 0.5$ & $11.9 \pm 0.5$ \\
\hline \multirow[t]{7}{*}{ Female } & \multirow[t]{4}{*}{ Spatial } & Swim time & $30.1 \pm 2.1$ & $38.9 \pm 1.9^{\mathrm{a}}$ & $33.3 \pm 2.5$ \\
\hline & & Swim distance & $519.1 \pm 38.0$ & $657.2 \pm 32.9^{a, b}$ & $526.6 \pm 41.1$ \\
\hline & & Corridor & $2.8 \pm 0.3$ & $1.9 \pm 0.2^{\mathrm{a}}$ & $2.3 \pm 0.3$ \\
\hline & & Swim speed & $16.6 \pm 0.4$ & $16.1 \pm 0.3$ & $15.5 \pm 0.5$ \\
\hline & \multirow[t]{3}{*}{ Cued } & Swim time & $19.8 \pm 1.9$ & $23.4 \pm 1.8$ & $20.5 \pm 2.4$ \\
\hline & & Swim distance & $272.0 \pm 26.6$ & $305.6 \pm 23.3$ & $256.2 \pm 31.7$ \\
\hline & & Swim speed & $14.8 \pm 0.6$ & $13.4 \pm 0.3$ & $12.9 \pm 0.5$ \\
\hline
\end{tabular}

a $P<0.05$ relative to adult social controls.

${ }^{\mathrm{b}} P<0.05$ relative to middle-aged enriched mice.

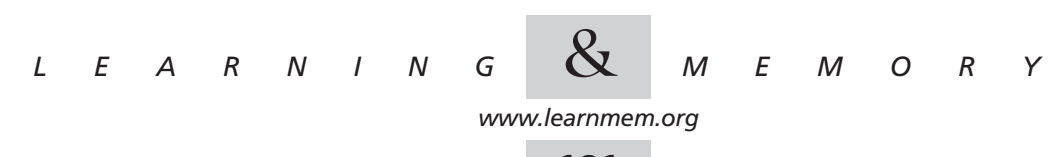



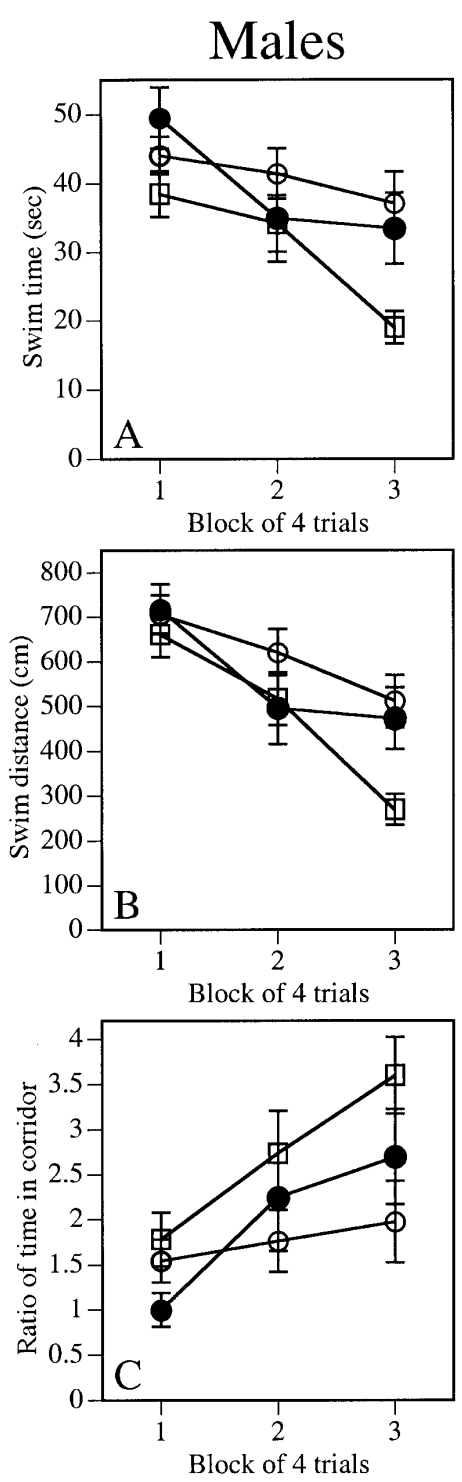

- - Middle-aged social control male

$\longrightarrow$ Middle-aged enriched male

Figure 1 Environmental enrichment reduced age-related impairments in acquisition of the spatial task in middle-aged enriched males relative to middle-aged social control males. Swim time $(A)$, swim distance $(B)$, and corridor ratio $(C)$ were recorded during each block of four spatial trials. Each point represents the mean \pm SEM of each group for four trials. Middle-aged social control males exhibited significantly slower swim times, longer swim distances, and less time in the corridor than adult social control males. In contrast, middle-aged enriched males and adult social control males did not differ in any measure. Open square represents adult social control males; open circle, middle-aged social control males; closed circle, middle-aged enriched males. Group means are shown in Table 2. this measure as well. Platform crossings did not differ among the groups (Fig. 5C).

As in males, the cued task was not affected by age or enrichment in females. Neither the Group effects (Table 2) nor the Trial x Group interactions were significant for any measure. Significant Trial effects in swim time (Fig. 3B) and swim distance indicated improvement during the course of testing $\left(F_{3,123}=15.0\right.$ and 10.9 , respectively, $\left.P<0.001\right)$.

\section{Comparison of Enrichment Effects on Memory in Males and Females}

Among middle-aged mice, enrichment significantly improved spatial acquisition, as indicated by a significant main effect of Enrichment in the swim distance measure $\left(F_{1,45}=5.1, P<0.03\right)$. Spatial retention was also facilitated by enrichment, as indicated by a significant improvement in the spatial proximity measure from the probe trial $\left(F_{1,45}=4.7, P<0.05\right)$. The cued task was unaffected by enrichment. Sex differences were observed in swim speed during the spatial task $\left(F_{1,45}=4.5, P<0.05\right)$, but not in any other measure of the spatial or cued tasks. No Sex $x$ Enrichment interactions were significant for any spatial or cued measure, suggesting a similar effect of enrichment on memory in middle-aged males and females.

\section{Neurochemical Measures: GAD and Synaptophysin}

Group means for GAD activity and synaptophysin levels are presented in Table 3. GAD activity was increased in the hippocampus of middle-aged enriched males relative to adult and middle-aged social control males $\left(F_{2,37}=4.4\right.$, $P<0.02$; posthocs $P<0.05)$. Neocortical GAD activity did not differ among the three male groups. Among females, hippocampal and neocortical GAD activities were unaffected by age or enrichment. In analyses of middle-aged mice only, GAD activities in the hippocampus and neocortex were unaffected by Sex and Enrichment, and the Sex $x$ Enrichment interactions were not significant for either brain region. However, in the hippocampus, the Sex effect $\left(F_{1,44}=3.9, P=0.056\right)$ and Sex $\mathrm{x}$ Enrichment interaction $\left(F_{1,44}=3.2, P=0.08\right)$ were nearly significant, reflecting the significant increase in hippocampal GAD activity revealed in middle-aged enriched males by the separate-sex ANOVA.

Neither hippocampal nor neocortical synaptophysin levels were altered by age or enrichment among males. Hippocampal and neocortical synaptophysin levels were also similar among the three female groups. In analyses of middle-aged mice only, synaptophysin levels in the hippocampus and neocortex were unaffected by Sex, either as a main effect or an interaction with Enrichment.

\section{Correlations Between Behavioral and Neurobiological Measures}

Because few group differences were observed in ANOVAs for GAD activity or synaptophysin, correlation analyses

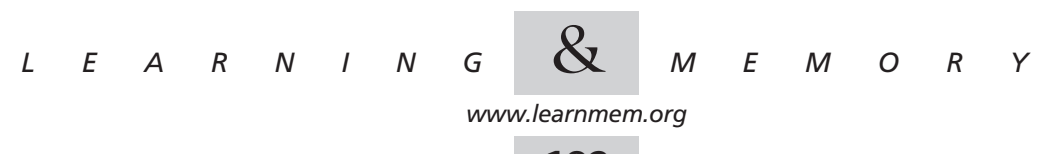




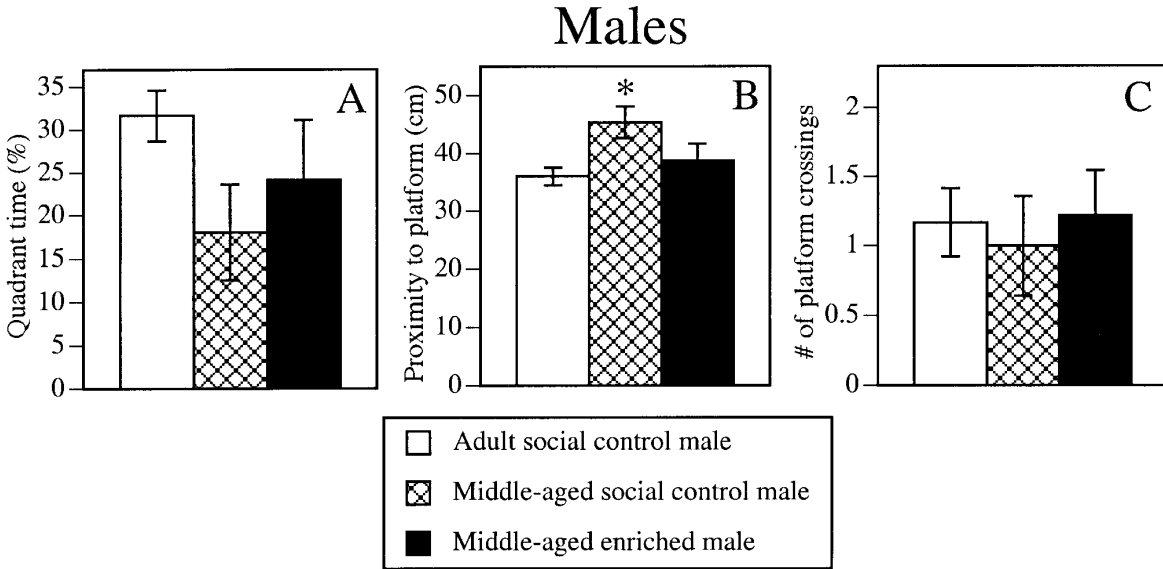

Figure 2 Enrichment also reduced the age-related memory impairment of males during the spatial probe trial. This improvement was particularly evident in the proximity measure $(B)$, in which middle-aged social control males swam further from the platform location than adult social control males $(* P<0.05)$, whereas middle-aged enriched males and adult social control males did not differ. Quadrant time $(A)$, proximity $(B)$, and platform crossings $(C)$ are presented. Open bar represents adult social control males; cross-hatched bar, middle-aged social control males; solid bar, middle-aged enriched males. Each bar represents the mean \pm SEM for each group.

were performed, including all three groups (each sex was analyzed separately). Among males, significant correlations were found between hippocampal synaptophysin and spatial swim time $(r=-0.336, P=0.039)$, and hippocampal synaptophysin and the spatial corridor $(r=0.325$, $P=0.046)$. In both cases, elevated synaptophysin was associated with better performance in the spatial task. No correlations were significant between GAD activity in either brain region and behavior among males. Among females, no significant correlations were observed between synaptophysin or GAD activity in either brain region and any behavioral measure.

\section{DISCUSSION}

The results of the present study indicate that environmental enrichment initiated during middle age can reduce age-related spatial reference memory deficits in middle-aged mice. An enrichment-induced improvement in middle-aged mice may be indicated by two outcomes as follows: (1) the lack of a difference between the adult social control and middleaged enriched groups combined with an age-related impairment in middle-aged social controls, and (2) a significant improvement in middle-aged enriched mice relative to middle-aged social controls. The first outcome suggests a beneficial effect of enrichment, because it indicates that enrichment reduces the age-related memory impairment. The second outcome illustrates a more robust effect, because it indicates a significant improvement relative to middle-aged social controls. In this study, most of the enrichment-induced benefit to spatial task acquisition and retention reflects the first outcome; middle-aged social control mice, but not middle-aged enriched mice, were signifi- cantly impaired relative to adult social controls. However, the second outcome was observed in one measure among females, as indicated by the significantly shorter swim distances of middle-aged enriched females relative to middleaged social control females. Although middle-aged enriched males did not perform better than middle-aged social control males in any measure, the absence of significant Sex x Enrichment interactions in ANOVAs restricted to middle-aged mice suggests a similar benefit of enrichment in middle-aged males and females. The effect of enrichment in both sexes, demonstrated here, was specific to spatial memory, as suggested by the similar performance of all groups during the cued trials.

Because GAD activity and synaptophysin levels were largely unchanged by aging or enrichment, the underlying neurobiological mechanisms of this effect remain unknown. In females, no neurochemical measurement differed among the groups or was associated with spatial memory. In males, hippocampal GAD activity was increased by enrichment, and elevated hippocampal synaptophysin was associated with better spatial memory. Although this association between high synaptophysin levels and better memory is consistent with previous findings, the correlations are weak in light of the numerous comparisons conducted. Together, the synaptophysin correlations, combined with a lack of association between GAD activity and
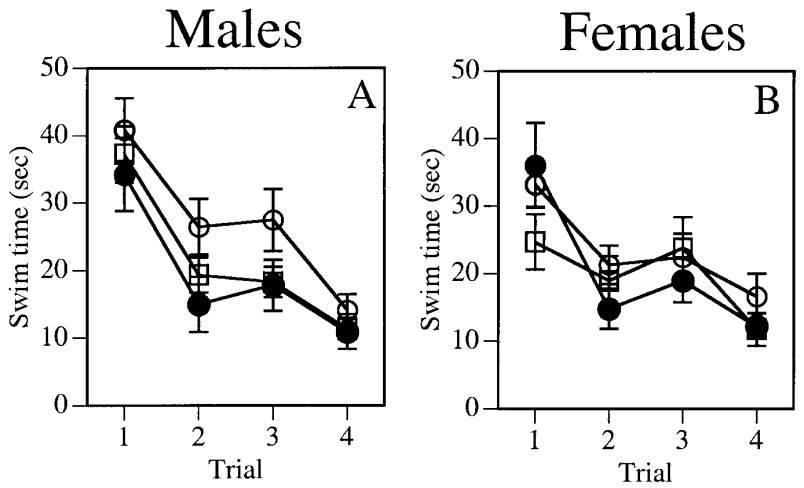

Figure 3 Neither age nor enrichment affected cued task performance in either sex. Swim time in males $(A)$ and females $(B)$ are presented. Open circles represent adult social controls, open squares represent middle-aged social controls, and filled circles represent middle-aged enriched. Each point represents the mean \pm SEM of each group for one trial.

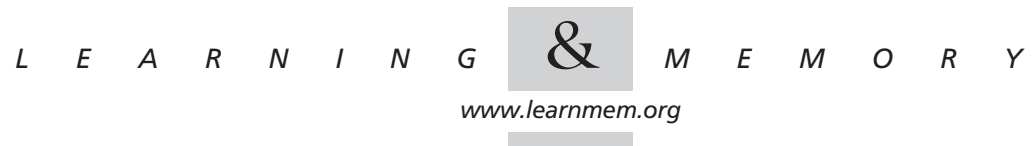



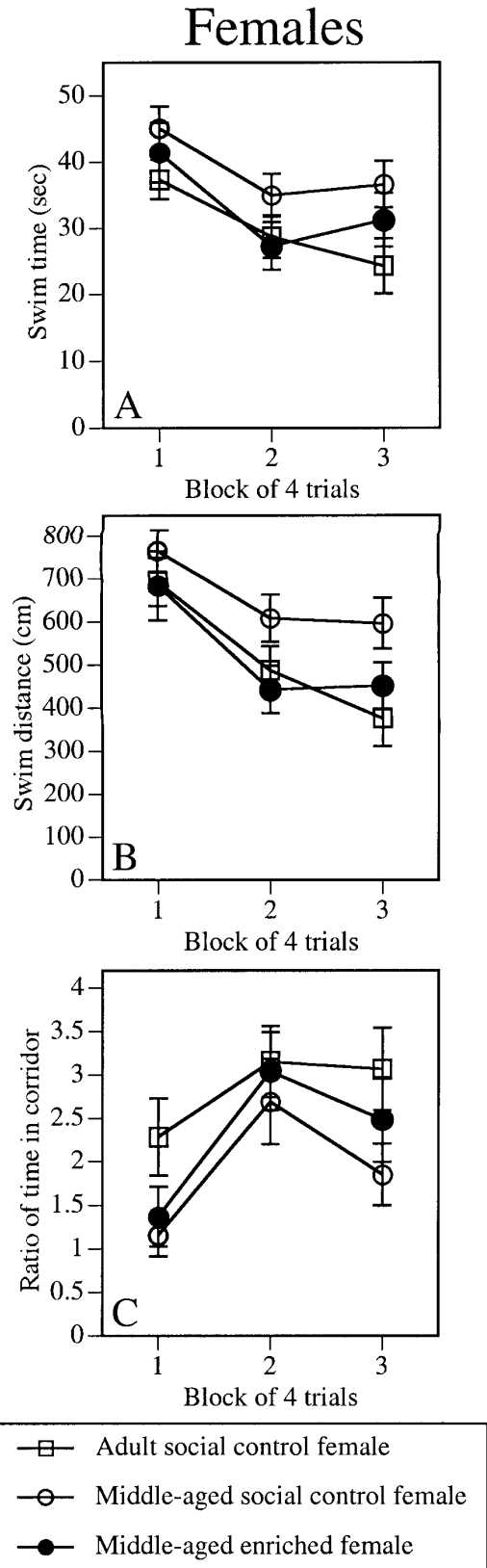

Figure 4 Environmental enrichment reduced age-related impairments in acquisition of the spatial task in middle-aged enriched females relative to middle-aged social control females. Swim time $(A)$, swim distance $(B)$, and corridor ratio $(C)$ were recorded during each block of four spatial trials. Each point represents the mean \pm SEM of each group for four trials. Middle-aged social control females exhibited significantly slower swim times, longer swim distances, and less time in the corridor than adult social control females. In contrast, middle-aged enriched females and adult social control females did not differ in any measure. Furthermore, middleaged social control females swam longer distances from the platform than middle-aged enriched females. Open squares represent adult social control females; open circles, middle-aged social control females; closed circles, middle-aged enriched females. Group means are shown in Table 2. behavior, suggest that alterations in either of these proteins may not play a role in the observed enrichment-induced memory improvements. However, we cannot entirely exclude the possibility that other factors may have contributed to the lack of enrichment- or age-induced differences in GAD activity or synaptophysin levels. For example, subregional differences in these measures would not have been detected in our dissections of the entire hippocampal and frontoparietal cortical regions. Also, subtle alterations may have fallen below the detection limit of our assay procedures. However, these possibilities are unlikely as we have shown previously that enrichment significantly increases synaptophysin in the frontoparietal cortex and whole hippocampus in 27-28 month-old female mice (Frick and Fernandez 2003). Nevertheless, other markers of GABAergic function (e.g., GABA receptor number or sensitivity) or synaptic function (e.g., post-synaptic markers) may be altered by enrichment.

The enrichment-induced reductions of age-related spatial memory deficits observed in the current study are consistent with previous reports of aged mice and middle-aged rats tested in the same task (Kempermann et al. 1998; Pham et al. 1999; Frick and Fernandez 2003). However, our improvements differ in magnitude from previous studies of middle-aged male rats (Pham et al. 1999) and middle-aged female mice (Kempermann et al. 1998), which used traditional multi-day water maze protocols. In a previous study, middle-aged enriched male rats performed significantly better than middle-aged isolated controls (no young adult controls were tested; Pham et al. 1999), whereas in our study, the effects of enrichment were largely due to improvements relative to adult social controls rather than to middle-aged social controls. However, in previous work with middleaged female mice (Kempermann et al. 1998), enriched females were superior to middle-aged social control females. Nevertheless, it is noteworthy that our enrichment effect is similar in magnitude to our own work in aged female mice tested in a multi-day water maze protocol (Frick and Fernandez 2003).

The smaller magnitude of our enrichment effect compared with that reported by Kempermann et al. (1998) and Pham et al. (1999) may be attributed to a number of factors, including: (1) the type of controls used, (2) the duration of enrichment, (3) the relatively low number of toys present in the home cage, or (4) the type of task used. First, we may not have observed as much of an effect of enrichment, because we used social controls rather than isolated controls (Winocur 1998). However, social housing is typical in many mouse colonies, so our data may have greater relevance to other studies of learning and memory than data gathered using isolated controls. Second, the present study utilized 25-29 d of enrichment by inclusion of new toys in the standard home cage. In contrast, those who report differences between middle-aged enriched and control groups

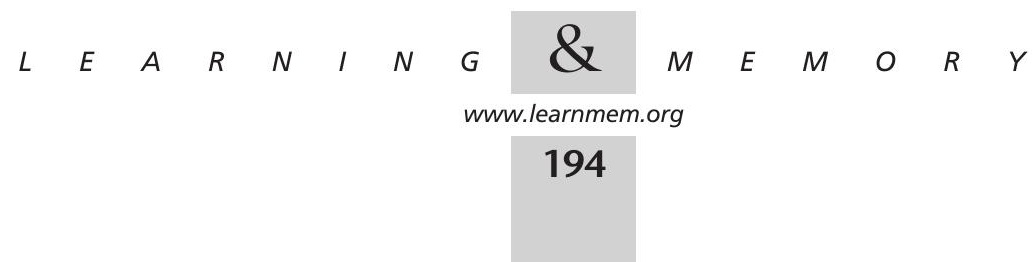


Females

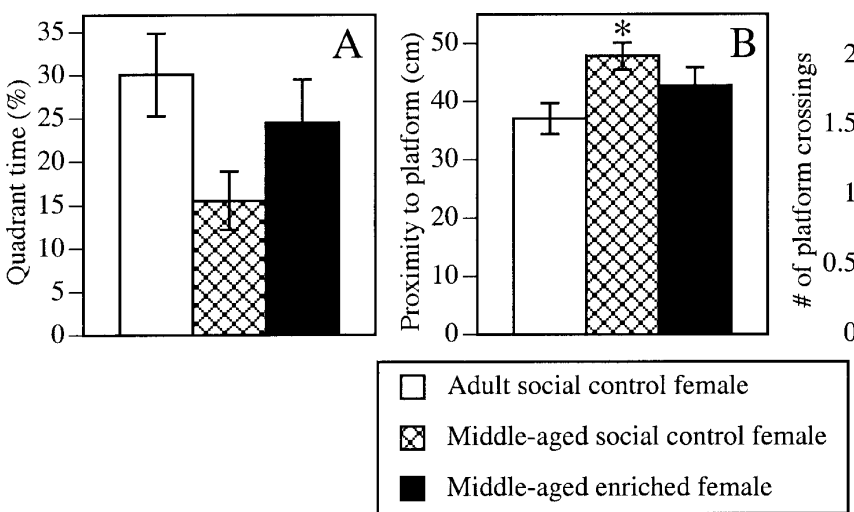

Figure 5 Enrichment also reduced the age-related memory impairment of females during the spatial probe trial. Similar to males, this improvement was particularly evident in the proximity measure $(B)$, in which middle-aged social control females swam further from the platform location than adult social control females $(* P<0.05)$, whereas middle-aged enriched females and adult social control females did not differ. There was also a strong trend for middle-aged enriched females to spend more time in the correct quadrant than middle-aged social control females. Quadrant time $(A)$, proximity $(B)$, and platform crossings $(C)$ are presented. Open bar represents adult social control females; cross-hatched bar, middle-aged social control females; closed bar, middle-aged enriched females. Each bar represents the mean \pm SEM for each group.

(Kempermann et al. 1998; Pham et al. 1999) utilized $40 \mathrm{~d}$ or 12 mo of enrichment. Third, mice in the present study were enriched in their home cage with relatively few toys present at a time, in contrast to other studies in which subjects were housed in large cages filled with numerous toys (Kempermann et al. 1998; Pham et al. 1999). Finally, the current study used a 1-day, rather than multi-day swim maze task. The 1-day task was used for two reasons, (1) to examine better the relationships between behavior and neurochemistry, and (2) because we have found that middle-aged male mice of this strain are not impaired relative to young mice using a multi-day protocol (Frick et al. 2000b). Although this protocol was challenging for middle-aged males, the increased difficulty of this task may diminish the beneficial effect of enrichment. Nevertheless, despite the use of social controls, a relatively short duration of enrichment, relatively few toys, and the 1-day water maze protocol, enriched middle-aged mice of both sexes displayed reduced agerelated spatial memory deficits relative to middle-aged social controls when both groups were compared with adult social controls. This finding suggests that relatively small amounts of enrichment can benefit middle-aged mice of either sex.

GAD activity was unaltered by aging or enrichment in females and was increased by enrichment in males only in the hippocampus. Interestingly, in males, this increase is the opposite of our predictions based on our previous neurochemical findings in middleaged mice of this strain (Frick et al. 2002). Given that hippocampal GAD activity was not correlated in either sex with performance in the spatial water maze task, it is unlikely that the increased GAD activity seen in the hippocampus of enriched males is related to the observed mnemonic improvements. Examination of other indicators of GABAergic function in middle-aged enriched males may help resolve this issue.

One puzzling aspect of the GAD activity data is the lack of age differences in both sexes. Although this is consistent with another report (Waller et al. 1983), our previous work using $\mathrm{C} 57 \mathrm{BL} / 6$ mice revealed that hippocampal GAD activity in 17-month-old females was significantly elevated relative to that of 5-month-old females, whereas neocortical and

Table 3. GAD and Synaptophysin Data for Each Group

\begin{tabular}{lllccc}
\hline Sex & Assay & Brain region & $\begin{array}{c}\text { Adult } \\
\text { social control }\end{array}$ & $\begin{array}{c}\text { Middle-aged } \\
\text { social control }\end{array}$ & $\begin{array}{c}\text { Middle-aged } \\
\text { enriched }\end{array}$ \\
\hline Male & GAD $^{\mathrm{a}}$ & Neocortex & $168.1 \pm 6.9$ & $173.7 \pm 6.6$ & $176.9 \pm 11.3$ \\
& & Hippocampus & $180.5 \pm 9.4$ & $168.5 \pm 7.8$ & $214.0 \pm 12.5^{\mathrm{c}}$ \\
& Synaptophysin $^{\mathrm{b}}$ & Neocortex & $0.93 \pm 0.02$ & $0.96 \pm 0.03$ & $0.94 \pm 0.05$ \\
& & Hippocampus & $1.32 \pm 0.07$ & $1.28 \pm 0.07$ & $1.13 \pm 0.07$ \\
Female & GAD & Neocortex & $186.3 \pm 10.3$ & $170.8 \pm 7.6$ & $159.5 \pm 8.3$ \\
& \multirow{2}{*}{ Synaptophysin } & Hippocampus & $211.4 \pm 20.2$ & $166.1 \pm 11.6$ & $164.2 \pm 19.2$ \\
& & Neocortex & $1.03 \pm 0.03$ & $1.03 \pm 0.04$ & $0.94 \pm 0.05$ \\
& & Hippocampus & $1.35 \pm 0.06$ & $1.39 \pm 0.06$ & $1.20 \pm 0.06$ \\
\hline
\end{tabular}

${ }^{a}$ Values represent the mean $\mathrm{nmol}$ product $/ \mathrm{hr} / \mathrm{mg}$ protein \pm SEM.

bValues represent mean \pm SEM MBS synaptophysin equivalents expressed as sample immunoreactivity relative to that of an equal amount of mouse brain standard.

${ }^{c} P<0.05$ relative to adult and middle-aged social controls.

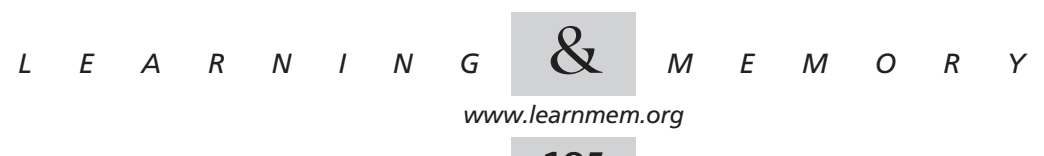


hippocampal GAD activity of 17-month-old males was significantly reduced relative to that of 5-month-old males (Frick et al. 2002). There are two possible explanations for the discrepancies. First, the control mice in the two studies differed in age by $2 \mathrm{mo}$, although it is unlikely that this age difference contributed to the inconsistency. A more likely explanation is the behavioral experience of the mice prior to the collection of brain tissue. In the present experiment, control mice received a total of $2 \mathrm{~d}$ of behavioral training and were killed on the second day. In our previous experiment, mice participated in a battery of behavioral tasks lasting $\sim 5 \mathrm{wk}$. Previous studies have shown that behavioral testing can significantly alter brain cholinergic and GABAergic function (Matthies et al. 1978; Caldji et al. 2000) and increase brain weight (Cummins et al. 1973).

Synaptophysin immunoreactivity was unaltered by aging and enrichment in either sex, although correlations in males suggest a relationship between elevated hippocampal synaptophysin and better spatial memory. Similarly, decreased synaptophysin immunocytochemistry is associated with impaired spatial memory in aging male rodents (Chen et al. 1995; Smith et al. 2000), despite the lack of overall decreases with age (Calhoun et al. 1998). Although this and other reports found no age-related changes in hippocampal and/or neocortical synaptophysin (Calhoun et al. 1998; Nicolle et al. 1999; Frick and Fernandez 2003), other studies demonstrate reductions in synaptophysin with age (Saito et al. 1994; Chen et al. 1995; Smith et al. 2000). Recent work indicates that synaptophysin is decreased only in certain subregions of the hippocampus (Smith et al. 2000), and thus, more discrete dissections of the hippocampus and neocortex may have revealed age-related alterations in this study. The current study is also inconsistent with enrichment-induced increases of synaptophysin and presynaptic vesicles in aged male rats (Saito et al. 1994; Nakamura et al. 1999), and with our recent finding that enrichment in 27 28-month-old female mice increases synaptophysin levels in both the hippocampus and neocortex (Frick and Fernandez 2003). The critical element in resolving this discrepancy may be age, as synaptophysin may not be affected early in the aging process, but may be stimulated by enrichment later on as neurodegeneration becomes more severe.

In conclusion, the present study indicates that environmental enrichment initiated during middle age can reduce age-related spatial reference memory impairments in middle-aged male and female mice. The behavioral response of males and females to enrichment was similar. Alterations in GAD activity and synaptophysin do not appear to underlie the improvement in either sex, and thus, the potential neurobiological mechanisms of this effect remain to be determined. Nevertheless, the behavioral data suggest that environmental enrichment is a cognitive enhancer in middleaged mice. The magnitude of this effect is similar to that found in studies using drugs to ameliorate age-related spatial memory decline (e.g., Baxter et al. 1994a,b; Markowska et al. 1994; Frick et al. 1996). Compared with drugs, enrichment is safer, less expensive, simpler to implement, and produces fewer side effects. Thus, environmental enrichment may be considered as a viable alternative to drug treatment for the prevention or reduction of some types of agerelated mnemonic decline.

\section{ACKNOWLEDGMENTS}

We thank Erica Stillner for assistance with behavioral testing. This work was supported by the National Science Foundation (NSF 9976623 to J.B.S.), the American Federation for Aging Research/ Pfizer (K.M.F.), and Yale University (K.M.F.).

The publication costs of this article were defrayed in part by payment of page charges. This article must therefore be hereby marked "advertisement" in accordance with 18 USC section 1734 solely to indicate this fact.

\section{REFERENCES}

Baxter, M.G., Lanthorn, T.H., Frick, K.M., Golski, S., Wan, R.-Q., and Olton, D.S. 1994a. D-cycloserine, a novel cognitive enhancer, improves spatial memory in aged rats. Neurobiol. Aging 15: 207-213.

Baxter, M.G., Rohrbach, K.W., Tam, W., Zaczek, R., Frick, K.M., Golski, S., Wan, R.-Q., and Olton, D.S. 1994b. Effects of linopirdine (DuP 996) and X9121 on age-related memory impairments and on the cholinergic system. Drug Dev. Res. 31: 186-196.

Berger-Sweeney, J., Berger, U.V., Sharma, M., and Paul, C.A. 1994. Effects of carbon dioxide-induced anesthesia on cholinergic parameters in rat brain. Lab. Anim. Sci. 44: 369-371.

Bradford, M.M. 1976. A rapid and sensitive method for the quantitation of microgram quantities of protein utilizing the principle of protein-dye binding. Anal. Biochem. 72: 248-254.

Brown, R.T. 1968. Early experience and problem-solving ability. J. Comp. Physiol. Psych. 65: 433-440.

Buttini, M., Akeefe, H., Lin, C., Mahley, R.W., Pitas, R.E., Wyss-Coray, T., and Mucke, L. 2000. Dominant negative effects of apolipoprotien E4 revealed in transgenic models of neurodegenerative disease. Neuroscience 97: 207-210.

Caldji, C., Francis, D., Sharma, S., Plotsky, P.M., and Meaney, M.J. 2000. The effects of early rearing environment on the development of GABAA and central benzodiazepine receptor levels and novelty-induced fearfulness in the rat. Neuropsychopharmocology 22: 219-229.

Calhoun, M.E., Kurth, D., Phinney, A.L., Long, J.M., Hengemihle, J., Mouton, P.R., Ingram, D.K., and Jucker, M. 1998. Hippocampal neuron and synaptophysin-positive bouton number in aging C57BL/6 mice. Neurobiol. Aging 19: 599-606.

Chen, K.S., Masliah, E., Mallory, M., and Gage, F.H. 1995. Synaptic loss in cognitively impaired aged rats is ameliorated by chronic human nerve growth factor infusion. Neuroscience 68: 19-27.

Cummins, R.A., Walsh, R.N., Budtz-Olsen, O.E., Konstantinos, T., and Horsfall, C.R. 1973. Environmentally-induced changes in the brains of elderly rats. Nature 243: 516-518.

Diamond, M.C. 1967. Extensive cortical depth measures and neuron size increases in the cortex of environmentally enriched rats. J. Comp. Neurol. 131: 357-364.

Diamond, M.C., Krech, D., and Rosenzweig, M.R. 1964. The effects of an enriched environment on the histology of the rat cerebral cortex. $J$. Comp. Neurol. 123: 111-119.

Diamond, M.C., Johnson, R.E., Protti, A.M., Ott, C., and Kajisa, L. 1985. Plasticity in the 904-day-old male rat cerebral cortex. Exp. Neurol. 87: 309-317.

Duffy, S.N., Craddock, K.J., and Nguyen, P.V. 2001. Environmental

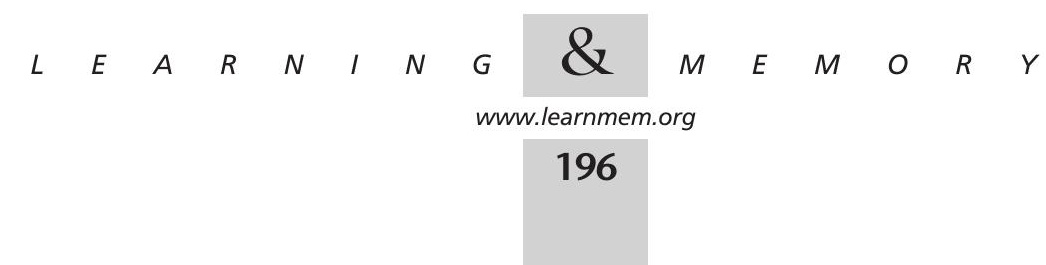


enrichment modifies the PKA-dependence of hippocampal LTP and improves hippocampus-dependent memory. Learn. Mem. 8: 26-34.

Evans, G.W., Brennan, P.L., Skorpanich, M.A., and Held, D. 1984. Cognitive mapping and elderly adults: Verbal and location memory for urban landmarks. J. Gerontol. 39: 452-457.

Frick, K.M. and Berger-Sweeney, J. 2001. Spatial reference memory and neocortical neurochemistry vary with the estrous cycle in C57BL/6 mice. Behav. Neurosci. 115: 229-237.

Frick, K.M. and Fernandez, S.M. 2003. Enrichment enhances spatial memory and increases synaptophysin levels in aged female mice Neurobiol. Aging (in press)

Frick, K.M., Baxter, M.G., Markowska, A.L., Olton, D.S., and Price, D.L. 1995. Age-related spatial reference and working memory deficits assessed in the water maze. Neurobiol. Aging 16: 149-160.

Frick, K.M., Gorman, L.K., and Markowska, A.L. 1996. Oxotremorine infusions into the medial septal area of middle-aged rats affect spatial reference memory and ChAT activity. Behav. Brain Res. 80: 99-109.

Frick, K.M., Stillner, E.S., and Berger-Sweeney, J. 2000a. Mice are not little rats: Species differences in a one-day water maze task. NeuroReport 11: 3461-3465

Frick, K.M., Burlingame, L.A., Arters, J.A., and Berger-Sweeney, J. 2000b. Reference memory, anxiety, and estrous cyclicity in C57BL/6NIA mice are affected by age and sex. Neuroscience 95: 293-307.

Frick, K.M., Burlingame, L.A., Delaney, S.S., and Berger-Sweeney, J. 2002. Sex differences in neurochemical markers that correlate with behavior in aging mice. Neurobiol. Aging 23: 145-158.

Gage, F.H., Dunnett, S.B., and Björklund, A. 1984. Spatial learning and motor deficits in aged rats. Neurobiol. Aging 5: 43-48.

Gallagher, M. 1997. Animal models of memory impairment. Phil. Trans. R. Soc. Lond. B. 352: 1711-1717.

Gallagher, M. and Pelleymounter, M.A. 1988. Spatial learning deficits in old rats: A model for memory decline in the aged. Neurobiol. Aging 9: 549-556

Globus, A., Rosenzweig, M.R., Bennett, E.L., and Diamond, M.C. 1973. Effects of differential experience on dendritic spine counts in rat cerebral cortex. J. Comp. Physiol. Psych. 82: 175-181.

Gower, A.J. and Lamberty, Y. 1993. The aged mouse as a model of cognitive decline with special emphasis on studies in NMRI mice. Behav. Brain Res. 57: 163-173.

Green, E.J. and Greenough, W.T. 1986. Altered synaptic transmission in dentate gyrus of rats reared in complex environments: Evidence from hippocampal slices maintained in vitro. J. Neurophysiol. 55: 739-750.

Green, E.J., Greenough, W.T., and Schlumpf, B.E. 1983. Effects of complex or isolated environments on cortical dendrites of middle-aged rats. Brain Res. 264: 233-240.

Greenough, W.T. and Volkmar, F.R. 1973. Pattern of dendritic branching in occipital cortex of rats reared in complex environments. Exp. Neurol. 40: 491-504.

Greenough, W.T., Wood, W.E., and Madden, T.C. 1972. Possible memory storage differences among mice reared in environments varying in complexity. Behav. Biol. 7: 717-722.

Greenough, W.T., Volkmar, F.R., and Juraska, J.M. 1973. Effects of rearing complexity on dendritic branching in frontolateral and temporal cortex of the rat. Exp. Neurol. 41: 371-378.

Greenough, W.T., West, R.W., and DeVoogd, T.J. 1978. Subsynaptic plate perforations: Changes with age and experience in the rat. Science 202: 1096-1098.

Greenough, W.T., McDonald, J.W., Parnisari, R.M., and Camel, J.E. 1986 Environmental conditions modulate degeneration and new dendrite growth in cerebellum of senescent rats. Brain Res. 380: 136-143.

Ickes, B., Pham, T.M., Sanders, L.A., Albeck, D.S., Mohammed, A.H., and Granholm, A.C. 2000. Long-term environmental enrichment leads to regional increases in neurotrophin levels in rat brain. Exp. Neurol. 164: 45-52.

Joseph, R. 1979. Effects of rearing and sex on maze learning and competitive exploration in rats. J. Psychol. 101: 37-43

Juraska, J.M. 1984. Sex differences in dendritic response to differential experience in the rat visual cortex. Brain Res. 295: 27-34
Juraska, J.M. and Meyer, M. 1986. Behavioral interactions of postweaning male and female rats with a complex environment. Dev. Psychobiol. 19: $493-500$

Juraska, J.M., Fitch, J.M., Henderson, C., and Rivers, N. 1985. Sex differences in the dendritic branching of dentate granule cells following differential experience. Brain Res. 333: 73-80.

Kempermann, G., Kuhn, H.G., and Gage, F.H. 1997. More hippocampal neurons in adult mice living in an enriched environment. Nature 386: 493-495.

. 1998. Experience-induced neurogenesis in the senescent dentate gyrus. J. Neurosci. 18: 3206-3212.

Markowska, A.L., Koliatsos, V.E., Breckler, S.J., Price, D.L., and Olton, D.S 1994. Human nerve growth factor improves spatial memory in aged but not in young rats. J. Neurosci. 14: 4815-4824.

Matthies, H., Rauca, C., and Liebmann, H. 1978. Changes in the acetylcholine content of different brain regions of the rat during a learning experiment. J. Neurochem. 23: 1109-1115.

Nakamura, H., Kobayashi, S., Ohashi, Y., and Ando, S. 1999. Age-changes of brain synapses and synaptic plasticity in response to an enriched environment. J. Neurosci. Res. 56: 307-315.

Nicolle, M.M., Gallagher, M., and McKinney, M. 1999. No loss of synaptic proteins in the hippocampus of aged, behaviorally impaired rats. Neurobiol. Aging 20: 343-348.

Nilsson, M., Perfilieva, E., Johansson, U., Orwar, O., and Eriksson, P.S. 1999. Enriched environment increases neurogenesis in the adult rat dentate gyrus and improves spatial memory. J. Neurobiol. 39: 569-578.

O'Connor, L.H., Nock, B., and McEwen, B.S. 1988. Regional specificity of $\gamma$-aminobutyric acid receptor regulation by estradiol Neuroendocrinology 47: 473-481.

Pham, T.M., Ickes, B., Albeck, D., Söderström, S., Granholm, A.C., and Mohammed, A.H. 1999. Changes in brain nerve growth factor levels and nerve growth factor receptors in rats exposed to environmental enrichment for one year. Neuroscience 94: 279-286.

Rampon, C., Tang, Y.-P., Goodhouse, J., Shimizu, E., Kyin, M., and Tsien, J.Z. 2000. Enrichment induces structural changes and recovery from nonspatial memory deficits in CA1 NMDAR1-knockout mice. Nature Neurosci. 3: 238-244.

Rosenzweig, M.R. and Bennett, E.L. 1996. Psychology of plasticity: Effects of training and experience on brain and behavior. Behav. Brain Res. 78: 57-65

Saito, S., Kobayashi, S., Ohashi, Y., Igarashi, M., Komiya, Y., and Ando, S. 1994. Decreased synaptic density in aged brains and its prevention by rearing under enriched environment as revealed by synaptophysin contents. J. Neurosci. Res. 39: 57-62

Schaie, K.W. 1993. The Seattle longitudinal studies of adult intelligence. Curr. Dir. Psych. Sci. 2: 171-175

Schlaf, G., Salje, C., Poethke, R., Felgenhauer, K., and Mäder, M. 1996. A novel enzyme-linked immunosorbent assay for determination of synaptophysin as compared with other quantification procedures. $J$. Neuroimmunol. 67: 59-65.

Sharps, M.J. and Gollin, E.S. 1987. Memory for object locations in young and elderly adults. J. Gerontol. 42: 336-341

Shimamura, A.P., Berry, J.M., Mangels, J.A., Rusting, C.L., and Jurica, P.J. 1995. Memory and cognitive abilities in university professors: Evidence for successful aging. Psychol. Sci. 6: 271-277.

Smith, T.D., Adams, M.M., Gallagher, M., Morrison, J.H., and Rapp, P.R. 2000. Circuit-specific alterations in hippocampal synaptophysin immunoreactivity predict spatial learning impairment in aged rats. $J$. Neurosci. 20: 6587-6593.

Soffié, M., Hahn, K., Terao, E., and Eclancher, F. 1999. Behavioural and glial changes in old rats following environmental enrichment. Behav Brain Res. 101: 37-49.

Tang, Y.-P., Wang, H., Feng, R., Kyin, M., and Tsien, J.Z. 2001. Differential effects of enrichment on learning and memory function in NR2B transgenic mice. Neuropharmacology 41: 779-790.

Tees, R.C. 1999. The influences of sex, rearing environment, and neonatal

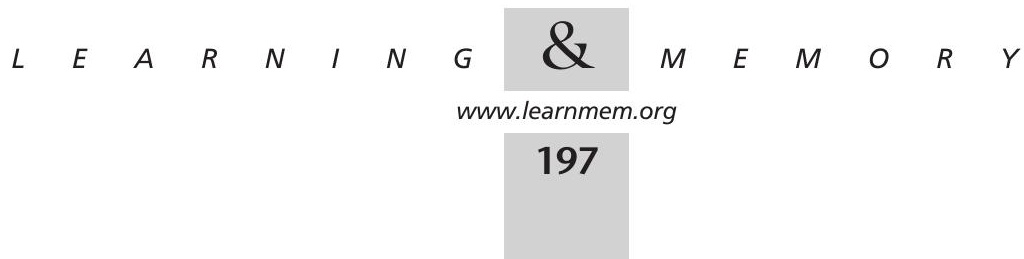




\section{Frick et al.}

choline dietary supplementation on spatial and nonspatial learning and memory in adult rats. Dev. Psychobiol. 35: 328-342.

Torasdotter, M., Metsis, M., Henriksson, B.G., Winblad, B., and

Mohammed, A.H. 1996. Expression of neurotrophin-3 mRNA in the rat visual cortex and hippocampus is influenced by environmental enrichment. Neurosci. Lett. 218: 107-110.

Torasdotter, M., Metsis, M., Henriksson, B.G., Winblad, B., and Mohammed, A.H. 1998. Environmental enrichment results in higher levels of nerve growth factor mRNA in the rat visual cortex and hippocampus. Behav. Brain Res. 93: 83-90.

Van Waas, M. and Soffié, M. 1996. Differential environmental modulations on locomotor activity, exploration and spatial behaviour in young and old rats. Physiol. Behav. 59: 265-271.

Waller, S.B., Ingram, D.K., Reynolds, M.A., and London, E.D. 1983. Age and strain comparisons of neurotransmitter synthetic enzyme activities in the mouse. J. Neurochem. 41: 1421-1428.
Warren, J.M., Zerweck, C., and Anthony, A. 1982. Effects of environmental enrichment on old mice. Dev. Psychobiol. 15: 13-18.

Williams, B.M., Luo, Y., Ward, C., Redd, K., Gibson, R., Kuczaj, S.A., and McCoy, J.G. 2001. Environmental enrichment: Effects on spatial memory and hippocampal CREB immunoreactivity. Physiol. Behav. 73: 649-658

Winocur, G. 1998. Environmental influences on cognitive decline in aged rats. Neurobiol. Aging 19: 589-597.

Woodcock, E.A. and Richardson, R. 2000. Effects of environmental enrichment on rate of contextual processing and discriminative ability in adult rats. Neurobiol. Learn. Mem. 73: 1-10.

Received June 3, 2002; accepted in revised form February 19, 2003.

$\begin{array}{llllllllllllllllllllllllll}L & E & A & R & N & I & N & G & \& & M & E & M & O & R & Y\end{array}$ www.learnmem.org 


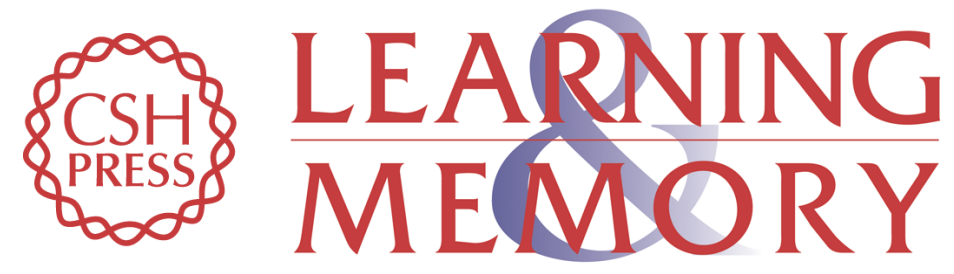

\section{Effects of Environmental Enrichment on Spatial Memory and Neurochemistry in Middle-Aged Mice}

Karyn M. Frick, Nancy A. Stearns, Jing-Yu Pan, et al.

Learn. Mem. 2003, 10:

Access the most recent version at doi:10.1101//m.50703

References This article cites 65 articles, 5 of which can be accessed free at:

http://learnmem.cshlp.org/content/10/3/187.full.html\#ref-list-1

License

Email Alerting Receive free email alerts when new articles cite this article - sign up in the box at the Service top right corner of the article or click here. 